\title{
LYAPUNOV STABILITY ANALYSIS TO SET UP A PI CONTROLLER FOR A MASS FLOW SYSTEM IN CASE OF A NON-SATURATING INPUT
}

\author{
Paolo Mercorelli \\ Institute of Product and Process Innovation \\ Leuphana University of Lueneburg \\ Volgershall 1, D-21339 Lueneburg, GERMANY
}

\begin{abstract}
This paper deals with the calculation of sufficient conditions for the stability of a mass flow controlled system. In order to analyse the stability and the dynamic performance of the controlled system a Lyapunov approach is proposed. Through this approach the condition of the two parameters which characterise the controller are calculated.
\end{abstract}

AMS Subject Classification: 49K15, 37N35, 34K35

Key Words: problems involving ordinary differential equations, dynamical systems in control, control problems

\section{Introduction and Motivation}

The usage of PID-type controllers is very frequent in industry, such that they constitute $90 \%$ of all the industrial controllers [1]. They are the most widely used controllers because of their simplicity and the few tuning parameters. Trial and error method for the tuning process is usually applied because there are difficulties to choose these parameters in case nonlinear systems. Furthermore, advanced PID controllers have been constructed for controlling complex and nonlinear systems.

$\begin{array}{lr}\text { Received: } & \text { October 4, } 2016 \\ \text { Revised: } & \text { November 20, } 2016 \\ \text { Published: } & \text { December 11, } 2016\end{array}$

(C) 2016 Academic Publications, Ltd. url: www.acadpubl.eu 
The goal of this work is to demonstrate sufficient conditions for parameters of a PI controller by means of Lyapunov approach for a mass flow system. This contribution is a mathematical extension of the results published in [2] and in [3] in case of no saturating inputs. This work consists of only one section devoted both to the mass flow model and the PI controller. The conclusion closes the contribution.

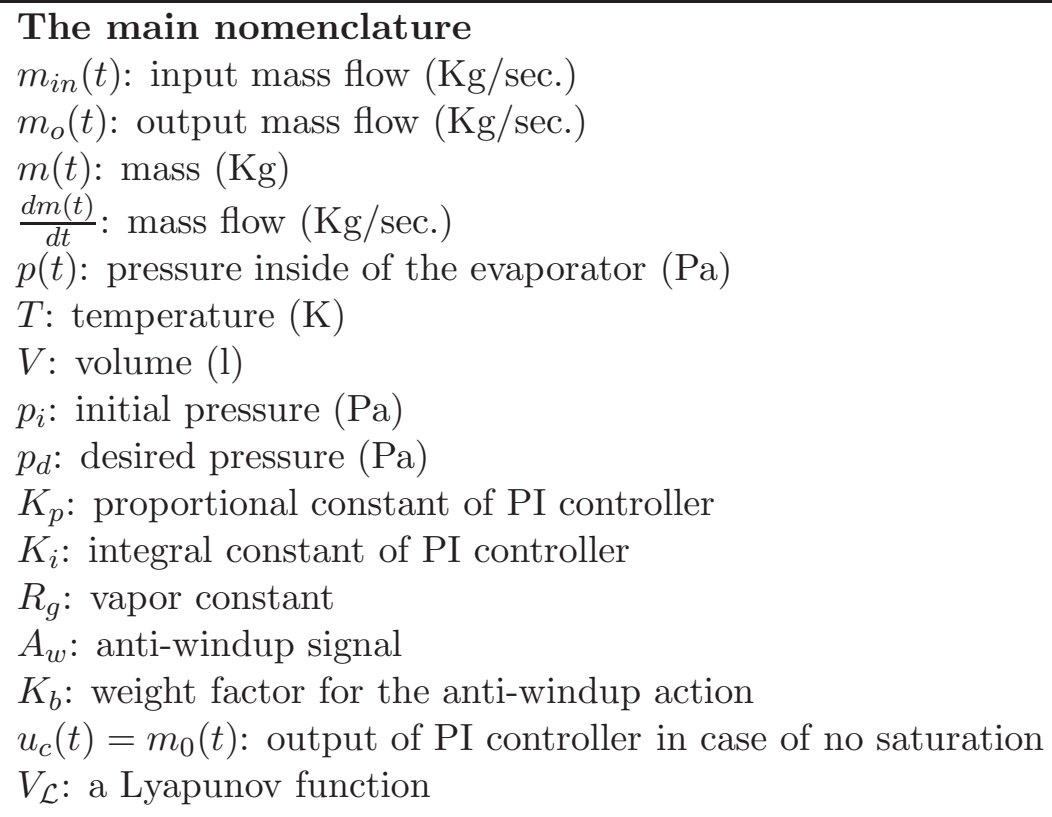

\section{The Flow Mass Model with PI Controller}

The dynamical model of the system consists of the mass flow equation and the ideal gas equation which is represented in (1) and (2). The considered model represents a viable approach for many heating systems and it is widely used in many technical fields. If limited or saturating input $m_{0}(t)$ is considered, it can be difficult to control the system because of the presence of the nonlinear element which is represented by the limit or by saturations which are always present in a real application.

$$
\begin{aligned}
\frac{d m(t)}{d t} & =m_{i}(t)-m_{o}(t), \\
\frac{d p(t)}{d t} & =\frac{d m(t)}{d t} \frac{R_{g} T}{V}
\end{aligned}
$$


in which $m_{i}(t)$ is a stepwise positive constant function.

Considering the following nonlinear PI controller for the system described above:

$$
u_{c}(t)=m_{o}(t)=K_{p}\left(p_{d}-p(t)\right)+K_{i} \int_{0}^{t}\left(p_{d}-p(\tau)\right) d \tau .
$$

Theorem 1. Let consider the system described by (1), (2) and (3), if

$$
\frac{d m_{0}(t)}{d t}>0
$$

and the three constant parameters $K_{p}, K_{i}$ and $K_{b}$ of the controller defined by (3) are such that $K_{p}<0$ and $K_{i}<0$, then the controlled system results to be asymptotically stable around the desired constant pressure $p_{d}$.

Proof. From the regulator defined by (3), the following expression is obtained:

$$
u_{c}(t)=m_{o}(t)=K_{p}\left(p_{d}-p(t)\right)+K_{i} \int_{0}^{t}\left(p_{d}-p(\tau)\right) d \tau
$$

and thus

$$
m_{o}(t)=\left(K_{p}\left(p_{d}-p(t)\right)+K_{i} \int_{0}^{t}\left(p_{d}-p(\tau)\right) d \tau\right) .
$$

Differentiating expression (5) it follows:

$$
\frac{d m_{o}(t)}{d t}=\left(-K_{p} \frac{d p(t)}{d t}+K_{i}\left(p_{d}-p(t)\right)\right) .
$$

From (4) (hypothesis of Theorem 1), it follows that:

$$
-K_{p} \frac{d p(t)}{d t}+K_{i}\left(p_{d}-p(t)\right)>0
$$

which is equivalent to prove that

$$
K_{p} \frac{d p(t)}{d t}+K_{i} p(t)<K_{i} p_{d}
$$

Considering the solution of

$$
K_{p} \frac{d p(t)}{d t}+K_{i} p(t)=0,
$$

then it must be

$$
p(t)=p_{i} e^{-\frac{K_{i}}{K_{p}} t}<\frac{p_{d}}{K_{p}} K_{i},
$$


where $p_{i}=p(0)$ with $p(0)>0$. From (9) and (10) the following condition on $K_{i}$ and $K_{p}$ is obtained:

$$
K_{i}>\frac{p(0)}{p_{d}} K_{p}
$$

Taking into consideration (10) and that $K_{i}<0$ as well $K_{p}<0$, it follows that:

$$
\frac{d p(t)}{d t}<0
$$

and thus from (2), being $\frac{V}{T R_{g}}>0$, it follows:

$$
\frac{d m(t)}{d t}=\frac{V}{T R_{g}} \frac{d p(t)}{d t}<0 .
$$

In order to show the asymptotical stability of the controlled system, the following Lyapunov function is chosen:

$$
V_{\mathcal{L}}(p(t))=\frac{1}{2}\left(p_{d}-p(t)\right)^{2}+K_{i} \int_{0}^{t}\left(p_{d}-p(t)\right)^{2} d \tau,
$$

in which the state of the system is considered together with the state of the integral action of the controller. Differentiating (14), it follows:

$$
\frac{d V_{\mathcal{L}}(p(t))}{d t}=-\left(p_{d}-p(t)\right)\left(\frac{d p(t)}{d t}-K_{i}\left(p_{d}-p(t)\right)\right)
$$

and considering that

$$
\frac{d p(t)}{d t}=\frac{d m(t)}{d t} \frac{R_{g} T}{V}
$$

then it follows that:

$$
\frac{d V_{\mathcal{L}}(p(t))}{d t}=-\left(p_{d}-p(t)\right)\left(\frac{d m(t)}{d t} \frac{R_{g} T}{V}-K_{i}\left(p_{d}-p(t)\right)\right) .
$$

From (7), being

$$
\left(p_{d}-p(t)\right)=\frac{d m_{o}(t)}{d t} \frac{1}{K_{i}}+\frac{d p(t)}{d t} \frac{K_{p}}{K_{i}}
$$

it follows that:

$$
\begin{aligned}
\frac{d V_{\mathcal{L}}(p(t))}{d t}=-\left(\frac{d p(t)}{d t} \frac{K_{p}}{K_{i}}+\frac{d m_{o}(t)}{d t} \frac{1}{K_{i}}\right) & \\
& \left(\frac{d m(t)}{d t} \frac{R_{g} T}{V}-\frac{d m_{o}(t)}{d t}-\frac{d p(t)}{d t} K_{p}\right) .
\end{aligned}
$$


From the fact that $\frac{R_{g} T}{V}>0, \frac{d m_{o}(t)}{d t}>0$ and according to (12) and (13) $\frac{d p(t)}{d t}<0$ and $\frac{d m(t)}{d t}<0$ respectively, then, if $K_{p}<0$ and $K_{i}<0$ as stated in Theorem 1 , the following sufficient Lyapunov condition on the asymptotical stability is guaranteed:

$$
\frac{d V_{\mathcal{L}}(p(t))}{d t}<0
$$

\section{Conclusions}

Stability conditions for setting parameters of a PI controller to be applied in a mass flow system are found. The analysis of the stability of the controlled system is proposed using a Lyapunov approach.

\section{References}

[1] M. Lelic and Z. Gajic, A reference guide to PID controllers in the nineties, In: Proceedings of PID '00: IFAC Workshop on Digital Control, 73-82, Terrassa, Spain, 2000.

[2] P. Mercorelli, R. Halbe, J. Goes, A Lyapunov based PI controller with an anti-windup scheme for a purification process of potable water, In: Proceedings of the IEEE International Conference on Control, Decision and Information Technologies, CoDIT 2014, 578-583, Metz, 2014.

[3] Paolo Mercorelli, An optimal and stabilising PI controller with an anti-windup scheme for a purification process of potable water, IFAC-PapersOnLine, 48, No. 25 (2015), 259-264. 
